\section{Spinal anaesthesia}

Spinal anaesthesia is normally performed by puncture of the dura and arachnoid mater in the lumbar region, and local anaesthetic is introduced directly into the cerebrospinal fluid (CSF) surrounding the nerve roots and spinal cord. The solution will spread longitudinally through the CSF and the drug will be taken up by the neuronal tissue. Whether an effective concentration results in a particular nerve will depend on its accessibility, lipid content and blood flow. 'The nerve roots, especially of the cauda equina, are easily accessible and will be exposed over a considerable surface area as long as the solution spreads to a particular root

\section{Factors affecting spread}

The most important determinants of a spinal anaesthetic are the factors which affect spread of solution through the CSF. Greene ${ }^{2}$ has enumerated 25 of these and recent controlled clinical trials, using loss of sensation to pinprick to define spread, have indicated the clinically important factors. This work has been reviewed $d^{2,3}$ and may be summarised as follows.

\section{Solution baricity}

Using 0.5 per cent tetracaine, Brown et al. ${ }^{4}$ found that baricity had a major effect on the spread of analgesia. The solution was injected at the third lumbar interspace in patients placed in the lateral horizontal position and tumed supine immediately afterwards. The hyperbaric solution resulted in a mean block to $T_{5}$ and isobaric to $T_{t 0}$. The hypobaric solutions gave a mean level of $T_{11}$, but the blocks were patchy and of poor quality.

Mean duration was longer with an isobaric than with a hyperbaric solution of similar dose. This was presumed to relate to the wider spread of the hyperbaric solution allowing absorption to take place over a greater surface area, and thus being faster. Increasing the dose injected from 10 to $15 \mathrm{mg}$ had no effect on the level of spread achieved with any solution, but increased the duration of them all.

\section{Patient posture}

Posture has been used since the time of Barker' ${ }^{s}$ classical descriptions to aid or restrict spread of injected solution. If a patient is turned supine immediately after injection at the third or fourth lumbar interspace, the solution will be at the apex of the lumbar spinal curve. Gravity will thus cause a hyperbaric solution to spread down from the apex in both sacral and thoracic directions. With a hyperbaric

\section{J.A.W. Wildsmith MD CH. FFARCS}

solution it is not necessary to use the Trendelenberg position to ensure spread to mid-thoracic level. Sinclair et $a l .{ }^{6}$ found that all it did was to increase the variability of height of block and to increase the incidence of blocks extending into the cervical region. Accentuation of the lumbar curve in pregnancy may explain in part the increased spread seen when spinal anaesthesia is performed with a hyperbaric solution for Caesarean section. Conversely, flexion of the hips in the supine position reduces the lumbar curve and has been shown to reduce the spread of hyperbaric solutions. ${ }^{\text {? }}$

A major reason for using posture to control the spread of hyperbaric solutions is to try to restrict spread to the lower limbs and perineum. Wildsmith $e t a l^{8}{ }^{8}$ investigated the effect of maintaining both the lateral and sitting positions for five minutes after the injection of hyperbaric or isobaric solutions of tetracaine. They concluded that if posture is to be used to control the spread of a hyperbaric solution, then the posture must be maintained for considerably longer than is often practiced. They also found that posture had no effect at all on the spread of a truly isobaric solution, which they recommended for use when a block restricted to the legs or perineum is required.

\section{Volume and rate of injection}

Increasing the volume of a spinal anaesthetic injection usually increases the dose of drug injected, so a study was devised in which a standard dose of tetracaine was dissolved in 1,2 or $4 \mathrm{ml}$ of isobaric solution. ${ }^{9}$ There was very little difference in mean spread with the different volumes, but the larger the volume injected, the greater was the range of blocks - i.e., predictability was reduced. Slowing the rate of injection of $4 \mathrm{ml}$ reduced the range of blocks produced and made the solution more predictablc again. It was concluded that the most predictable spinal blocks might be produced by injecting a low volume solution at a slow rate.

\section{Patient characteristics}

Many anaesthetists relate the dose of local anaesthetic that they use for a spinal to the patient's height or weight. While restricted spread is sometimes seen in the very thin patient, and the opposite in the obese, many studies have found that spread correlates very poorly with patient size.

Department of Anaesthetics, Royal Infirmary, Edinburgh EH3 9YW, Scotland 
certainly within the adult range. For instance, MeCulloch and Littlewood ${ }^{10}$ have shown that there is some increase in spread in the obese patient, but the range of blocks is so wide that this is of very little predictive help. Level of block was totally unrelated to patient height. Similarly, some correlation has been shown between paticnt age and intrathecal spread, ${ }^{11,12}$ but again the range of blocks seen in any particular age group is still too wide for the information to be of any practical help.

\section{Effect of clinical interactions}

The results of the studies outlined above have indicated how the major factors affect the spread of local anaesthetic solution after intrathecal injection. However, it is important to appreciate that these studies were performed in healthy patients under very carefully controlled conditions. In the routine clinical situation variations in technique, differences in solution composition and individual patient factors (e.g., distortion of the spine with age) may individually or together result in different effects on spread.

For instance, Axelsson et al..$^{13}$ studied the spread of plain bupivacaine 0.5 per cent (a slightly hypobaric solution) in patients who were sitting for two minutes after injection and then placed in the lithotomy position. They found that ecphalad spread was proportional to the logarithm of the volume injected. Again, Chambers et $a l^{14}$ found that volume had no effect on the spread of hyperbaric 0.5 per cent bupivacaine, but that there was an effect on the spread of hyperbaric 0.75 per cent bupivacaine. Others ${ }^{15,16}$ have in fact demonstrated some relationship between volume injected and the spread of hyperbaric 0.5 per cent bupivacaine.

Such contradictory results may be due to a number of factors, including simple chance. It is important to remember that any technique of spinal anaesthesia results in a range of blocks, even when it is applied consistently by a single practitioner. Therefore it is not surprising that there should be some variation between the results of studics in which there may be subtle, seemingly irrelevant variations in technique, drug composition and patient characteristics. Too many investigators have not appreciated the importance of keeping every factor completely constant except the one being studied.

\section{Factors affecting duration}

Studies investigating the duration of spinal blockade vary considerably in their definitions of duration and this has made interpretation difficult. ${ }^{17}$ In addition, the patient who has undergone an abdominal operation under spinal anaesthesia has little interest in the duration of block in the feet, which is thus of little clinical relevance. However, recent work has shown that the main determinants of duration are the drug used ${ }^{18-22}$ and the dose injected, ${ }^{4,23,8}$

It is common practice to add vasoconstrictors to spinal anacsthetic solutions. The assumption is that the efficacy and the duration will be increased because of delayed vascular absorption. Recent controlled studies have shown that no clinically significant prolongation of effect is produced by the addition of epinephrine to lignocaine, bupivacaine or amethocaine. ${ }^{14,24,25}$ Phenylephrine does produce a significant prolongation in the duration of tetracaine, but a more marked effect may be produced simply by increasing the dose of local anesthetic that is injected.

\section{Drugs and recommendations}

Virtually every local anaesthetic that has been produced has been used for spinal anaesthesia. Given solutions equipotent in concentration and of the same baricity, the only variation to be expected in clinical effect is in duration of action, although there is some evidence that there may be subtle differences. For instance, tetracaine is said to be associated with a greater incidence of tourniquet discomfort than bupivacaine. ${ }^{26}$ Generally, clinical decisions will very much depend on what is readily available and that is governed mainly by commercial factors.

The ideal spinal anaesthetic preparation should contain no preservatives since these may damage the nerve fibres which only acquire a protective layer of perineurium after passing through the dura mater. The preparation should be in a form which enables the anaesthetist to adjust its baricity (by adding water, saline or dextrose) prior to use, but still produce a relatively small volume to inject. Tetracaine is available as a one per cent (isobararic) solution and a crystalline preparation, both of which meet these requirements.

Most other drugs specifically marketed for intrathecal use are dissolved in a dextrose solution and behave like hyperbaric tetracaine. Hyperbaric bupivacaine has recently become available and is becoming very popular, although it does have a very high dextrose concentration. The plain solution of bupivacaine is used widely, but has two slight drawbacks. It is slightly hypobaric at $37^{\circ} \mathrm{C}$ and has to be injected in relatively large volumes (3-4 ml) to ensure an adequate dose. The net effect is that plain bupivacaine, while producing the same mean spread as isobaric tetracaine in supine patients, produces a much wider range of blocks. ${ }^{9.12}$ It is a very unpredictable solution ${ }^{27}$ and should be reserved for surgery of the perineum and distal part of the lower limbs since blocks extending no higher than $L_{2}$ are seen fairly frequently. If the patient is kept sitting for a short while after the administration of plain bupivacaine, slightly higher blocks will be produced because it is slightly hypobaric and will move upwards. Plain tetracaine (a truly isobaric solution) can be used with 
confidence for any procedure on the lower limb, yet has a much lower incidence of excessively high blocks than plain bupivacaine.

Bupivacaine and tetracaine have one disadvantage in common - they are both relatively long-acting local anaesthetics. Their durations may be manipulated to some extent by varying the dose, but for many procedures a shorter-acting agent is better. A hyperbaric preparation of lidocaine is available and the plain solution of lidocaine two per cent may be used also. Like plain bupivacaine it produces a wide range of blocks. ${ }^{19}$

\section{References}

1 Greene NM. Review: uptake and elimination of local anesthetics during spinal anesthesia. Anesth Analg 1983; 62: 1013-24.

2 Greene NM. Distribution of local anesthetic solutions within the subarachnoid space. Anesth Analg 1985; 64: 715-30.

3 Wildsmith JAW, Rocco AG. Current concepts in spinal anesthesia. Reg Anesth 1985; 10: 119-24.

4 Brown DT, Wildsmith JAW, Covino BC, Scon DB. Effect of baricity on spinal anesthesia with arnethocaine. $\mathrm{Br} J$ Anaesth 1980; 52: 589-96.

5 Barker $A E$. Clinical experiences with spinal analgesia in 100 cases. Br Med. J. 1907; 1: 665.

6 Sinclair CJ, Scotl DB, Edstrom $H H$. Effect of the Trendelenberg position on spinal anaesthesia with hyperbaric bupivacaine. Br J Anaesth 1982; 54: 497-500.

7 Smith TC. The lumbar spine and subarachnoid block. Anesthesiology 1968; 29: 60-4

8 Wildsmith JAW, MCClure JH, Brown DT, Scott DB. Effects of posture on the spread of isabaric and hyperbaric amethocaine. Br J Anaesth 1981; 53: 273-8.

9 McClure JH, Brown DT, Wildsmith JAW. Effect of injected volume and speed of injection on the spread of spinal anaesthesia with isobaric amethocainc. $\mathrm{Br} \mathrm{J}$ Anaesth 1982; 54: 917-20

10 McCulloch WJD, Littlewood DG. Influence of obcsity on spinal analgesia with isobaric $0.5 \%$ bupivacaine. Br $J$ Anaesth 1986; 58: 610-4.

11 Cameron $A E$, Arnold $R W$, Ghoris $M W$, Jamieson $V$. Spinal aralgesia using bupivacaine $0.5 \%$ plain, Variations in the extent of block with patien! age. Anaesthesia 1987; 36: 318-22

12 Pitkanen $M$, Hapaniemi $L$, Touminen $M$, Rosenberg $P H$. Influence of age on spinal anaesthesia with isobaric $0.5 \%$ bupivacaine. Br J Anaesth 1984; 56: 279-84.

13 Axelsson $K H$. Edstrom $H H$, Widman $G B$. Spinal anacsthesia with glucose free $0.5 \%$ bupivacaine - effects of different volumes. Br I Anaesth 1984; 56: 271-8.
14 Chambers WA, Littlewood DB, Edstrom $H H$, Scot DB Spinal anaesthesia with hyperbaric bupivacaine: effects of concentration and volume administered. $\mathrm{Br} J$ Anaesth 1982; 54: 75-80

15 Axelsson $K H$, Edstrom HH, Widman GB. Spinal anaesthesia with hyperbaric $0.5 \%$ bupivacaine - effects of volume. Acta Anaesthesiol Scand 1982; 26: 439-45.

16 Sundnes $K O$, Vagenes $P$, Skretting $P$, Lind $P$, Edstrom $H H$. Spinal anaesthesia with hyperbaric bupivacaine. Effects of volume of solution. Br J Anaesth 1982; 54: 69-74

17 Chambers WA, Littlewood DG, Lagan MR, Scott DB. Effect of added epinephrine on spinal anesthesia with lidocaine. Anesth Analg 1981; 60: 417-20.

18 Cummings $G C$, Bambes $D B$, Edstrom $H H$, Rubin AP. Subarachnoid blockade with bupivacaine. A comparison with cinchocaine. Brit J Anaesth 1984; 56: 573-9.

19 McKeown DW, Stewan K, Littlewood DG, Wildsmith.JAW. Spinal anesthesia with plain solutions of lidocaine $2 \%$ and bupivacaine 0.5\%. Reg Anesth 1986; $11: 68-71$.

20 Marsirand $T$, Sorensen $M$, Andersen $S$. Spinal anaesthesia with $0.75 \%$ bupivacaine and $0.5 \%$ amethocaine in $5 \%$ glucose. Br J Anaesth 1985; 57: $971-5$.

21 Moore DC. Spinal anesthesia: bupivacaine compared with tetracaine. Anesth Analg 1980; 59: 743-50.

22 Skretting $P$, Vaagenes $P$, Sundnes $K O$, Edstrom $H H$, Lind $B$. Subarachnoid anaesthesia: compurison of hyperbaric solutions of bupivacaine and amethocaine. $\mathrm{Br} J$ Anaesth 1984; 56: 155-9.

23 Chambers WA. Editorial: intrathecal bupivacaine. $\mathrm{Br} \mathrm{J}$ Anaesth 1982; 54: 799-801.

24 Chambers WA, Littlewood DG, Scott DB. Spinal anesthesia with hyperbaric bupivacaine: effect of added vasoconstrictors. Anesth Analg 1982; 61: 49-52.

25 Armstrong IR, Littlewood DG, Chambers WA. Spinal anesthesia with tetracaine - effect of added vasoconstrictors. Anesth Anaig 1983; 62: 793-5.

26 Racco AG, Concepcion MA, Sheskey MC, Murray $E$, Edstrom $H H$, Covino BG. A double-blind evaluation of intrathecal bupivacaine without glucose and a standard solution of hyperbaric tetracaine. Reg Ancsth 1984; 9: $1-7$.

27 Logan MR, McClure JH, Wildsmith JAW. Plain bupivacaine - an unpredictable spinal anaesthetic agent. $\mathrm{Br} \mathbf{J}$ Anaesth 1986; 58: 292-6. 